
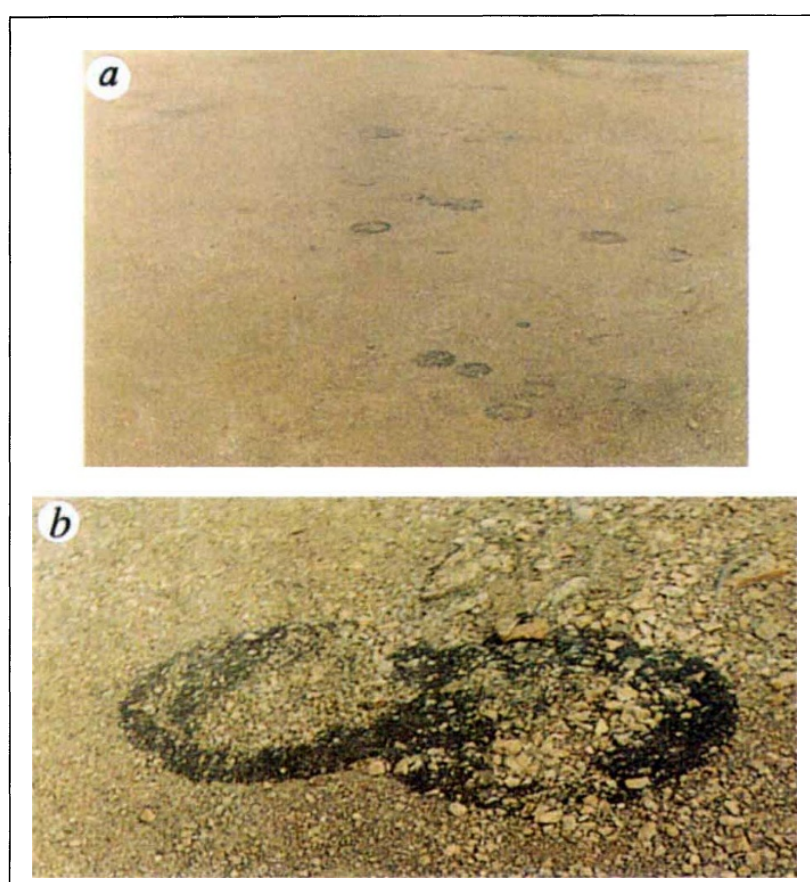

Aerial photographs of Minturn circles. a, Twenty-four circles on a boulder field of Precambrian gneisses. The largest circle is approximately $60 \mathrm{~m}$ across. Many of them have been disturbed by frost-boils. $b$, Two ring-shaped, partly overlapping circles; each ring is $59 \mathrm{~m}$ across.

melting of the Inland Ice, the syenite blocks became exposed on the flat surface of the ice.

Transport of melt water from a cold ice cap occurs at the surface in a multitude of meandering streams which may evolve around segments that are gradually isolated from the active streams as more or less ring-shaped structures. Superficial moraine will slide down into these isolated ring-shaped structures. In some cases, thin moraine may be deposited, whereas in others moraine could fill the ring structures. In the latter case, solar heating of the moraine may cause subsequent melting whereby the outer and inner rim melts away and a circle is produced.

One problem with this explanation is that cut-off segments from meandering streams rarely attain a perfectly round shape. Alternatively, Minturn circles may have formed in pot-holes made by streams on the surface of the Inland Ice. When the Inland Ice finally melted, the circular and ring-shaped accumulations of syenite debris would then have been

deposited very gently.

\section{Peter W. Uitterdijk Appel}

Geological Survey of Denmark

and Greenland,

$\emptyset$ ster Voldgade 10 ,

DK 1350 Copenhagen, Denmark

1. Weertman, J. J. Glaciol. 3, 965-978 (1971).

2. Boulton, G. S. J. Glaciol. 9, 213-229 (1970).

\title{
A newly defined interleukin-1?
}

SIR - Okamura et al. ${ }^{1}$ report the cloning of a novel, stress-induced cytokine from mouse liver which has biological actions in $\mathrm{T}$ cells that are strikingly reminiscent of interleukin-12 (IL-12). The polypeptide chain of this molecule, termed interferon$\gamma$-inducing factor, or IGIF, has no apparent similarity to sequences in protein or nucleotide databases ${ }^{1}$. To pursue further the possible kinship of IGIF to existing cytokine families ${ }^{2}$ (notably the haematopoietic group of regulators that includes IL-12), we have used fold recognition methods to classify IGIF, as protein structure is often a better measure of evolutionary relationship than is primary sequence.

Two algorithms that rely on very different potential functions to score sequence-structure compatibility -



Structural alignment of IGIF with human IL-1 cytokines. Representative IL-1 $\alpha, I L-1 \beta$ and IL-1ra folds are superposed following Murzin et $a l^{5}$ and aligned to the IGIF sequence by threading ${ }^{3,4}$, structure prediction and conserved residue patterns ${ }^{5}$. $\beta$-Strands are boxed and numbered 1 to 12 ; white residues contribute to the hydrophobic core ${ }^{5}$; the dashed bar marks the region of highest sequence similarity; dots designate alignment gaps; italicized cysteines in IL-1ra form the only disulphide bridge in this family. IGIF exhibits $19 \%$ and $12 \%$ positional identity to $\mathrm{IL}-1 \beta$ and IL-1 $\alpha$, respectively; by comparison, the latter two molecules show $23 \%$ sequence identity.
123D (ref. 3) and ProFIT (ref. 4) threaded the mature IGIF sequence through protein fold databases and drew consistent, top matches to the IL-1 $\beta$ structure (represented by Protein Data Bank locus $4 I 1 B$ ), a fold unrelated to haematopoietic factors ${ }^{2}$. A structurally based comparison of IGIF with IL-1 $\alpha$, IL-1 $\beta$ and receptor antagonist (IL-1ra) chains (see figure) shows a parsimonious alignment over the length of the respective sequences that comprise the twelve $\beta$-strands of the distinctive ' $\beta$ trefoil' fold ${ }^{5}$. Significant stretches of similarity indicated by this alignment are further evidence of the IGIF homology to the IL-1 family. A corresponding three-dimensional IGIF model built from the IL-1 $\beta$ framework displays the robust features of a native-like protein fold ${ }^{4,6}$.

This structural proposition has several important implications. The "unusual leader sequence" of IGIF $^{1}$ may be analogous to the IL-1 $\beta$ pro-domain, which must be cleaved for optimal secretion and biological activity; IGIF maturation at the Asp $\uparrow$ Asn site is probably mediated by an IL-1 $\beta$ convertase-like enzyme ${ }^{7}$. Also, an IL-1 binding paradigm, based on extensive mutagenesis studies ${ }^{7}$ and recently defined by the receptor complex structure of IL-1ra (ref. 8), may extend to the recognition of IGIF by a signalling complex that perhaps involves IL-1receptor subunits. If this model holds, IGIF could exert its biological actions with an IL-1-like NF- $\mathrm{B}$ signalling strategy $^{7}$, distinct from the JAK/STAT pathway of IL-12.

We suggest that IGIF is a member of the IL-1 family of cytokines that function in the immune and inflammatory response ${ }^{7}$, and tentatively propose a structurally accurate designation of 'IL-1 $\gamma$ '.

\section{J. Fernando Bazan \\ Jackie C. Timans}

Robert A. Kastelein

Department of Molecular Biology,

DNAX Research Institute,

Palo Alto, California 94304, USA

1. Okamura, H. et al. Nature 378, 88-91 (1995).

Sprang, S. R. \& Bazan, J. F. Curr. Opin. struct. Biol. 3 815-827 (1993)

3. Alexandrov, N. N., Nussinov, R. \& Zimmer, R. M. Pacif Symp. Biocomputing ' 96 (eds Hunter, L. \& Klein, T. E.) 53-72 (World Scientific, Singapore, 1995).

4. Flockner, H., Braxenthaler, M. \& Sippl, M. J. Proteins 23, 376-386 (1995)

5. Murzin, A. G., Lesk, A. M. \& Chothia, C. J. molec. Biol. 223, 531-543 (1992).

6. Levitt, M. J. molec. Biol. 226, 507-533 (1992)

7. Dinarello, C. A. FASEB J. 8, 1314-1325 (1994)

8. Schreuder, H. Cytokine 7, 599, Abstr. A23 (1995)

\section{Scientific Correspondence}

Scientific Correspondence is intended to provide a forum in which readers may raise points of a scientific character. Priority will be given to letters of fewer than 500 words and five references. 